\title{
Peculiarities of Raman scattering in nanometric superionic conductors $\mathrm{Cu}_{6} \mathrm{PS}_{5} \mathrm{Br}$
}

\author{
${ }^{1}$ Studenyak I.P., ${ }^{1}$ Buchuk R.Yu., ${ }^{2}$ Kranjcec M., ${ }^{1}$ Stephanovich V.O., \\ ${ }^{1}$ Panko V.V. and ${ }^{3}$ Kokenyesi S. \\ ${ }^{1}$ Uzhhorod National University, 46 Pidhirna St., 88000 Uzhhorod, \\ Ukraine; E-mail: studenyak@dr.com \\ ${ }^{2}$ Geotechnical Department Varaždin, University of Zagreb, 7 Hallerova \\ Aleja, 42000 Varaždin, Croatia; E-mail: m_krahjcec@yahoo.com \\ ${ }^{3}$ University of Debrecen, 18/a Bem tér, 4028 Debrecen, Hungary; \\ E-mail: kiki@tigris.unideb.hu
}

Received: 08.04.2009

\begin{abstract}
Superionic conductors $\mathrm{Cu}_{6} \mathrm{PS}_{5} \mathrm{Br}$ are obtained in nanocrystalline state with ballmilling. Phonon spectra of micro- and nano-powders are studied using Raman spectroscopy. Due to reduction of crystallite size, we have observed essential low-frequency shifts of the Raman scattering bands, broadening of the latter and the corresponding intensity decrease. Specific features of the Raman spectra of nanometric superionic conductors are explained predominantly by their surface phonon modes.
\end{abstract}

Keywords: nanocrystals, superionic conductors, Raman scattering

PACS: $63.50 .+\mathrm{x} ; 78.30 . \mathrm{Hv}$

UDC: 535.36

\section{Introduction}

$\mathrm{Cu}_{6} \mathrm{PS}_{5} \mathrm{Br}$ crystals belong to the family of compounds with argyrodite structure $[1,2]$. They are characterised by high concentration of disordered vacancies and possess both superionic and ferroelastic properties. High ionic conductivity at the room temperature [3, 4] determines potential possibilities of their practical applications as solid electrolyte sources of energy, sensors and highly efficient capacitors.

$\mathrm{Cu}_{6} \mathrm{PS}_{5} \mathrm{Br}$ crystals belong to the cubic system at the room temperature (the space group $F \overline{4} 3 m$ ) and two phase transitions (PTs) occur at low temperatures: a ferroelastic one at $T_{\mathrm{c}}=268 \pm 2 \mathrm{~K}$ and a superionic one at $T_{s}=166-180 \mathrm{~K}[3,4]$. Below the ferroelastic PT point $\mathrm{Cu}_{6} \mathrm{PS}_{5} \mathrm{Br}$ belongs to the monoclynic system (the space group $C c$ ) and the superionic PT reveals some features of an isostructural transformation [5]. Anomalous behaviour of dielectric, calorimetric and acoustic properties has been detected in the region of PTs mentioned above [3, 6-8]. Temperature studies performed with polarization 
optical technique have shown that the domain structure [9] and optical birefringence [10] of $\mathrm{Cu}_{6} \mathrm{PS}_{5} \mathrm{Br}$ crystal are observed at $T<T_{\mathrm{c}}$. Domain structure, thermal expansion, ultrasonic velocity and an $x, T$-phase diagram of the mixed crystals $\mathrm{Cu}_{6} \mathrm{PS}_{5} \mathrm{I}_{\mathrm{x}} \mathrm{Br}_{1-\mathrm{x}}$ have been studied in the work [11], whereas the Raman scattering, optical absorption and the luminescence have been dealt with in [4, 12-15]. The studies of the optical absorption edge in $\mathrm{Cu}_{6} \mathrm{PS}_{5} \mathrm{Br}$ crystal have evidenced existence of excitons below the superionic PT temperature, which undergo considerable changes with increasing temperature. The transition into superionic state results not only in variations of the exciton structure, but also in appearance of exponential contributions in the long-wavelength absorption edge. At $T>T_{\mathrm{s}}$ the temperature behaviour of the exponential parts has been successfully described by the empirical Urbach rule $[12,13]$.

In spite of the fact that the optical properties of bulk crystals of $\mathrm{Cu}_{6} \mathrm{PS}_{5} \mathrm{Br}$ superionic conductors have been studied extensively enough, researches of their changes due to transition to micro- or nanometric sizes only begin. Since the nanometric superionic conductors are of outstanding interest for the physics of nanoionic materials and nanosensors, the present work is aimed at investigations of specific features of the Raman scattering spectra in micro- and nanocrystalline superionic conductors $\mathrm{Cu}_{6} \mathrm{PS}_{5} \mathrm{Br}$.

\section{Experimental}

$\mathrm{Cu}_{6} \mathrm{PS}_{5} \mathrm{Br}$ single crystals were grown using a chemical vapour transport technique. The micro- and nanocrystalline powders of various grain sizes were obtained with ball-milling the material in a cylindrical stainless-steel vial, using hardened steel balls. The grain size reduction achieved during each milling step was followed by measuring the X-ray diffraction spectra (XRD) of the powders with a horizontal Siemens diffractometer using the $\mathrm{Cu} \mathrm{K} \mathrm{K}_{\alpha 1}$ radiation. The XRD analysis has confirmed that the lattice structure of $\mathrm{Cu}_{6} \mathrm{PS}_{5} \mathrm{Br}$ is preserved in the nanocrystalline samples, though the diffraction peaks become broader and less pronounced with decreasing size. The average grain size parameters for different duration times were determined following from the XRD patterns. Raman scattering measurements were performed on a double grating monochromator LOMO DFS-24, the excitation being provided by a $\mathrm{He}-\mathrm{Ne}$ laser $(632.8 \mathrm{~nm})$. The error of width contour registration did not exceed $1 \mathrm{~cm}^{-1}$ and the intensity distortion was within the limits of $2-4 \%$.

\section{Results and discussion}

We have performed Raman scattering studies of the bulk crystals and micro- and nanocrystalline powders of $\mathrm{Cu}_{6} \mathrm{PS}_{5} \mathrm{Br}$ obtained by millings of different durations (see Fig. 1). A number of separate groups of bands are observed in the Raman spectrum of the bulk crystals [4]. In the low-frequency region (i.e., below $100 \mathrm{~cm}^{-1}$ ) the bands corresponding to diffusive-type vibrations of $\mathrm{Cu}$ atoms and $\mathrm{Cu}-\mathrm{Br}$ bond vibrations are visible. In the region close to $315 \mathrm{~cm}^{-1}$ a broad asymmetric band has been revealed, resulting from superimposition of doubly degenerate $E$ mode and triply degenerate $F_{2}$

Ukr. J. Phys. Opt. 2009, V10, №3 


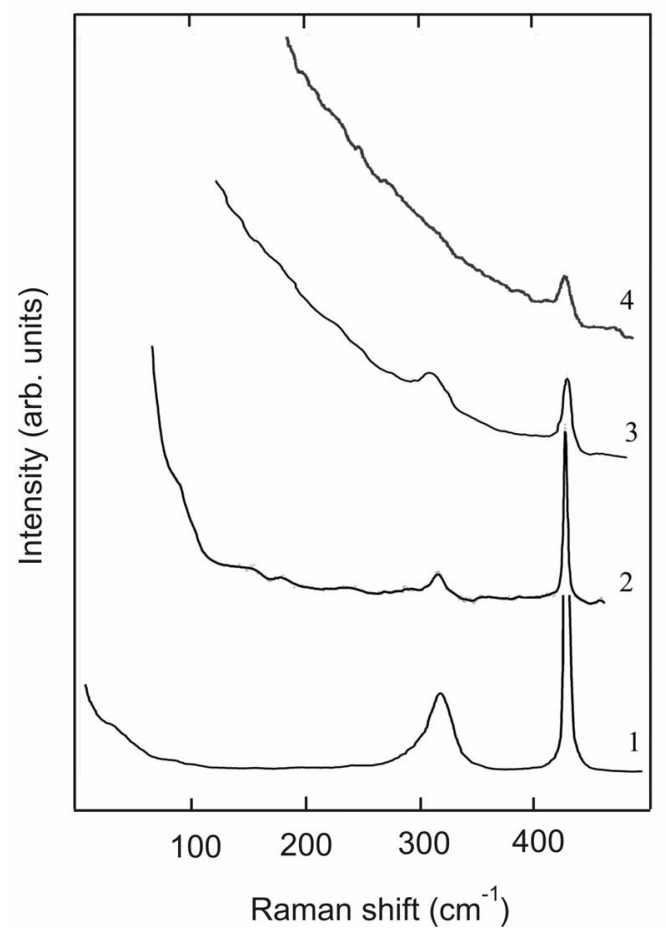

Fig. 1. Raman spectra of bulk $\mathrm{Cu}_{6} \mathrm{PS}_{5} \mathrm{Br}$ crystals (1) and micro- (2) and nanocrystalline powders of $\mathrm{Cu}_{6} \mathrm{PS}_{5} \mathrm{Br}$ with different average grain sizes: $38 \mathrm{~nm}(3)$ and $15 \mathrm{~nm}$ (4).

mode. A band corresponding to $A_{1}$ symmetry vibration is observed in the frequency region of $400-450 \mathrm{~cm}^{-1}$, which is the most pronounced in the spectra. Finally, two bands are revealed in the spectra in the region of $500-600 \mathrm{~cm}^{-1}$. They have been related to TO and LO vibrations of $F_{2}$ mode corresponding to internal stretching vibrations of tetrahedral $\mathrm{PS}_{4}{ }^{3-}$ groups [4].

A considerable increase in Rayleigh scattering, masking the lowfrequency Raman bands, is observed in nanocrystalline $\mathrm{Cu}_{6} \mathrm{PS}_{5} \mathrm{Br}$ powders (Fig. 1). Hence only the Raman bands located above $100 \mathrm{~cm}^{-1}$ could be detected. The spectra of the microcrystalline powder with the average grain size of $10 \mu \mathrm{m}$ and the nanocrystalline powder with the average grain size of $38 \mathrm{~nm}$ contain two distinct maxima, the higher-frequency one corresponding to an $A_{1}$ symmetry vibration and the lower-frequency one being a superposition of $E$ and $F_{2}$ symmetry modes. The crystallite size reduction results in a low-frequency shift of the both bands, their broadening and decrease in intensity. Moreover, in the nanocrystalline powders with the average grain size of $15 \mathrm{~nm}$ the band corresponding to the superimposition of the $E$ and $F_{2}$ symmetry modes, is totally smeared and only the maximum corresponding to the $A_{1}$ symmetry vibration is observed.

A considerable low-frequency shift of the Raman bands and their broadening occurring in nanometric crystals are most often explained by confinement-related relaxation of selection rules due to small crystallite sizes [16] and surface phonon modes [17]. The former factor seems to be hardly possible in our case because, according to the calculations [18], the minimal crystallite size under studies $(15 \mathrm{~nm})$ is too large to ascribe the observed features of size-related behaviour of the Raman band parameters to phonon confinement. Hence, the changes in the Raman spectra observed with decreasing nanocrystallite size could be assigned to surface phonon modes.

It should be noted that, contrary to the case of bulk crystals, the contribution of surface phonons to the Raman spectrum of nanocrystalline powders should be taken into account independently of exciting beam probing depth [18]. Therefore, for the spherical microcrystals of diameter $d$ one might expect Raman observation of a series of surface 
phonon modes with the quantum numbers $l=1,2,3, \ldots$ corresponding to

$$
\varepsilon(\omega)=-\frac{(l+1)}{l} \varepsilon_{m},
$$

where $\varepsilon_{m}$ is the dielectric constant of the medium surrounding the microcrystals [19]. The intensity of these modes in nanocrystals decays as $1 / r^{l-1}$ with increasing distance from the surface of the sphere, with the exception of a so-called Fröhlich mode $(l=1)$ which has a constant amplitude over the whole volume of the sphere. The Raman scattering efficiency in a small spherical crystal is given by [19]

$$
S=C|a \beta+b|^{2}\left\langle E^{2}\right\rangle \Delta(K, k),
$$

where $C$ is a constant, the parameters $a$ and $b$ give respectively the contributions of atomic displacement and electro-optical effect to the scattering, $\beta=Z / M\left(\omega_{T O}^{2}-\omega^{2}\right), Z$ is the effective charge, $M$ the reduced mass, $\omega_{T O}$ the long-wave transverse optical phonon frequency, and $\left\langle E^{2}\right\rangle$ the volume- and thermal-averaged squared field amplitude of the surface mode. Here

$$
\Delta(K, k)=\frac{1}{\pi} \frac{k^{\prime \prime}+1 / R}{\left(K-k^{\prime}\right)^{2}+\left(k^{\prime \prime}+1 / R\right)^{2}},
$$

where $R$ denotes the radius of the sphere, $K$ the radial wave number of the bulk phonon defined from the momentum conservation law, and $k^{\prime}$ and $k^{\prime \prime}$ are real and imaginary parts of the complex radial wave number introduced in order to include both the bulk phonons (real values in the case of damping effects being neglected) and the surface phonons (imaginary values) in the same formulation.

In order to estimate the contribution of surface phonon modes to the spectra measured experimentally we have fitted the $A_{1}$ Raman band by a superposition of two Lorentzian contours. The corresponding results are shown in Fig. 2. It is clearly seen from Table 1 that the $A_{1}$ band is well fitted by the two peaks, the lower-frequency one being broader than the higher-frequency peak. It should be noted that the averaged ratio of intensities referred to the surface and bulk phonons depends strongly on the grain size. Decrease in the latter results in larger contribution of the lower-frequency band and the resulting $A_{1}$ band shifts towards lower energies and broadens. Such the behaviour enables

Table 1. Spectral positions and halfwidths of the "bulk" and surface phonons in $\mathrm{Cu}_{6} \mathrm{PS}_{5} \mathrm{Br}$.

\begin{tabular}{|c|c|c|c|c|}
\hline \multirow{2}{*}{ Compounds } & \multicolumn{2}{|c|}{ "Bulk" phonon } & \multicolumn{2}{c|}{ Surface phonon } \\
\cline { 2 - 5 } & $\omega\left(\mathrm{cm}^{-1}\right)$ & $\Gamma\left(\mathrm{cm}^{-1}\right)$ & $\omega\left(\mathrm{cm}^{-1}\right)$ & $\Gamma\left(\mathrm{cm}^{-1}\right)$ \\
\hline Bulk single $\mathrm{Cu}_{6} \mathrm{PS}_{5} \mathrm{Br}$ crystals & 425 & 3.1 & - & - \\
\hline Microcrystalline powders $(10 \mu \mathrm{m})$ & 424 & 2.8 & 422 & 1.8 \\
\hline Nanocrystalline powders $(38 \mathrm{~nm})$ & 423 & 6.7 & 421 & 7.7 \\
\hline Nanocrystalline powders $(15 \mathrm{~nm})$ & 421 & 6.9 & 418 & 11.1 \\
\hline
\end{tabular}

Ukr. J. Phys. Opt. 2009, V10, №3 

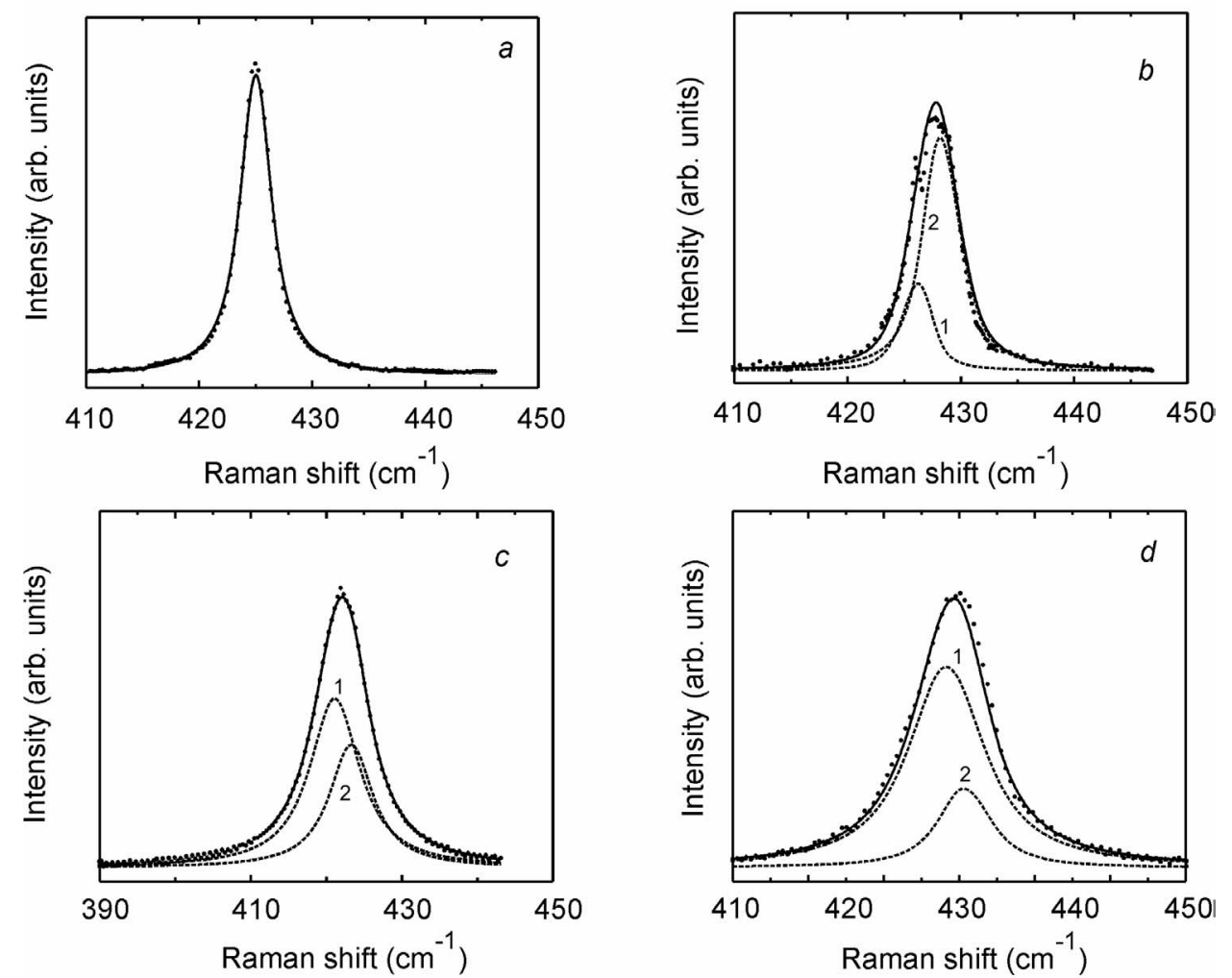

Fig. 2. Part of the Raman spectrum that includes the most intense $A_{1}$ band for the bulk single $\mathrm{Cu}_{6} \mathrm{PS}_{5} \mathrm{Br}$ crystals (a) and the micro- and nanocrystalline powders of $\mathrm{Cu}_{6} \mathrm{PS}_{5} \mathrm{Br}$ (the average grain sizes of $10 \mu \mathrm{m}$ (b), $38 \mathrm{~nm}$ (c), and $15 \mathrm{~nm}$ (d)) and simulation of the spectrum by the two Lorentzian contours corresponding to the surface (1) and "bulk" (2) phonons whose frequencies and halfwidths are given in Table 1.

us to attribute the broader lower-frequency bands to the surface phonons in nanocrystalline superionic conductors $\mathrm{Cu}_{6} \mathrm{PS}_{5} \mathrm{Br}$.

Let us point out that the mode located at $425 \mathrm{~cm}^{-1}$ represents a fully symmetrical polar vibration for the hypothetic case of an ideal free $\mathrm{PS}_{4}$ tetrahedron. However, this vibration becomes slightly polar due to effect of the crystal field. The polarity increases with the size decrease due to a breakdown and changes in the chemical bonds occurring for the tetrahedra directly at the nanocrystal surface. That is why our explanation of the shift and broadening observed in the Raman spectra with the average size reduction, which involves increasing contribution of the surface phonon scattering seems to be quite reasonable.

\section{Conclusions}

Nanocrystalline superionic $\mathrm{Cu}_{6} \mathrm{PS}_{5} \mathrm{Br}$ conductors are obtained with ball-milling and their average size is estimated from the direct XRD measurements. A considerable increase in Rayleigh scattering, masking the low-frequency Raman bands, is observed with decreasing average grain size in the nanocrystalline $\mathrm{Cu}_{6} \mathrm{PS}_{5} \mathrm{Br}$ powders. The effect is also 
accompanied by a low-energy shift, a broadening and intensity decrease in the phonon bands. The evolution of the Raman spectra occurring as a result of decreasing crystallite size is explained predominantly by the surface phonon modes, of which contribution to the Raman spectrum then increases due to higher surface-to-volume ratio.

\section{Acknowledgement}

The authors are grateful to the State Fund for Fundamental Research of Ukraine for the financial support under project F25.2/067.

\section{References}

1. Kuhs W F, Nitsche $R$ and Scheunemann K, 1978. The crystal structure of $\mathrm{Cu}_{6} \mathrm{PS}_{5} \mathrm{Br}$, a new superionic conductor. Acta Cryst. B 34: 64-70.

2. Nilges $T$ and Pfitzner A, 2005. A structural differentiation of quaternary copper argirodites: Structure - property relations of high temperature ion conductors. Z. Kristallogr. 220: 281-294.

3. Studenyak I P, Kovacs Gy Sh, Orliukas A S and Kovacs E T, 1992. Temperature variations of dielectric and optical properties in $\mathrm{Cu}_{6} \mathrm{PS}(\mathrm{Se})_{5} \mathrm{Hal}$ superionics and ferroelastics in the range of phase transitions. Izv. AN SSSR, Ser. Fiz. 56: 86-93.

4. Studenyak I P, Stefanovich V O, Kranjčec M, Desnica D I, Azhnyuk Yu M, Kovacs Gy Sh and Panko V V, 1997. Raman scattering studies of $\mathrm{Cu}_{6} \mathrm{PS}_{5} \mathrm{Hal}(\mathrm{Hal}=\mathrm{Cl}, \mathrm{Br}, \mathrm{I})$ fast-ion conductors. Solid State Ionics 95: 221-225.

5. Haznar A, Pietraszko A and Studenyak I P, 1999. X-ray study of the superionic phase transition in $\mathrm{Cu}_{6} \mathrm{PS}_{5} \mathrm{Br}$. Solid State Ionics 119: 31-36.

6. Fiechter S, Eckstein J and Nitsche R, 1983. Vapour growth of argyrodite-type ionic conductors $\mathrm{Cu}_{6} \mathrm{PS}_{5} \mathrm{Hal}$. J. Cryst. Growth 61: 275-283.

7. Skritskii V, Valyavichus V, Samulionis V, Studenyak I P, Kovacs Gy Sh and Panko V V, 1989. Temperature dependences of elastic properties in $\mathrm{Cu}_{6} \mathrm{PS}_{5} \mathrm{Br}$ superionic single crystals. Fiz. Tverd. Tela 31: 234-236.

8. Samulionis V, Banys J, Vysochanskii Y and Studenyak I, 2006. Investigation of ultrasonic and acoustoelectric properties of ferroelectric-semiconductor crystals. Ferroelectrics 336: 29-38.

9. Kaynts D I, Studenyak I P, Nebola I I and Horvat A A, 2003. Ferroelastic domains in $\mathrm{Cu}_{6} \mathrm{PS}_{5} \mathrm{X}(\mathrm{X}=\mathrm{I}, \mathrm{Br}, \mathrm{Cl})$ crystals. Ferroelectrics 290: 23-27.

10. Studenyak I P, Kranjčec M, Suslikov L M, Kovacs Gy Sh and Hadmashy Z P, 2002. Birefringence in $\mathrm{Cu}_{6} \mathrm{PS}_{5} \mathrm{Br}$ crystals. Ukr. Fiz. Zhurn. 47: 447-450.

11. Girnyk I, Kaynts D, Krupych O, Martunyuk-Lototska I and Vlokh R, 2003. x,T- phase diagram of the $\mathrm{Cu}_{6} \mathrm{PS}_{5} \mathrm{I}_{\mathrm{x}} \mathrm{Br}_{1-\mathrm{x}}$ mixed crystals. Optical, dilatation and ultrasonic velocity studies. Ukr. J. Phys. Opt. 4: 147-153.

12. Studenyak I P, Kranjčec M, Kovacs Gy Sh, Panko V V, Azhnyuk Yu M, Desnica I D, Borets O M and Voroshilov Yu V, 1998. Fundamental optical absorption edge and exciton-phonon interaction in of $\mathrm{Cu}_{6} \mathrm{PS}_{5} \mathrm{Br}$ superionic ferroelastic. Mat. Sci. Engin. B 52: 202-207.

Ukr. J. Phys. Opt. 2009, V10, №3 
13. Studenyak I P, Kranjcec M, Kovacs Gy Sh, Panko V V, Desnica I D, Slivka A G and Guranich P P, 1999. The effect of temperature and pressure on the optical absorption edge in $\mathrm{Cu}_{6} \mathrm{PS}_{5} \mathrm{X}(\mathrm{X}=\mathrm{Cl}, \mathrm{Br}, \mathrm{I})$ crystals. J. Phys. Chem. Sol. 60: 1897-1904.

14. Kranjčec M, Studenyak I P, Kovacs Gy Sh and Mitrovcij V V, 2002. Compositional disordering and some structural and optical parameters of $\mathrm{Cu}_{6} \mathrm{P}\left(\mathrm{S}_{1-\mathrm{x}} \mathrm{Se}_{\mathrm{x}}\right)_{5} \mathrm{Br}$ mixed crystals. Mat. Sci. Engin. B 95: 107-110.

15. Studenyak I P, Stephanovich V O, Bilanchuk V V, Panko V V and Studenyak Ya I, 2004. Influence of structural disordering on phonon and electron spectra of $\mathrm{Cu}_{6+\delta} \mathrm{PS}_{5} \mathrm{Br}$ superionic crystals. Func. Mat. 11: 363-366.

16. Ingale A and Rustagi K C, 1998. Raman spectra of semiconductor nanoparticles: Disorder-activated phonons. Phys. Rev. B 58: 7197-7204.

17. Hwang Y N, Park S H and Kim D, 1998. Size-dependent surface phonon mode of CdSe quantum dots. Phys. Rev. B 59: 7285-7288.

18. Gomonnai A V, Voynarovych I M, Solomon A M, Azhniuk Yu M, Kikineshi A A, Pinzenik V P, Kis-Varga M, Daroczy L and Lopushansky V V, 2003. X-ray diffraction and Raman scattering in SbSI nanocrystals. Mat. Res. Bull. 38: 1767-1772.

19. Ruppin R, 1975. Thermal fluctuations and Raman scattering in small spherical crystals. J. Phys. C: Solid State Phys. 8: 1969-1978.

Studenyak I.P., Buchuk R.Yu., Kranjcec M., Stephanovich V.O., Panko V.V. and Kokenyesi S., 2009. Peculiarities of Raman scattering in nanometric superionic conductors $\mathrm{Cu}_{6} \mathrm{PS}_{5} \mathrm{Br}$. Ukr.J.Phys.Opt. 10: 150-156.

Анотація. Суперіонні провідники $\mathrm{Cu}_{6} P S_{5} B r$ були отримані у нанокристалічному стані 3 використанням кульового млину. Методом спектроскопії комбінаиійного розсіяння світла досліджено фононні спектри мікро- $i$ нанорозмірних порошків. При зменшенні розміру кристалів нами спостерігався суттєвий зсув смуги комбінаційного розсіяння у низькочастотну область, ï̈ розширення $i$ відповідне зменшення інтенсивності. Особливості поведінки спектрів комбінаційного розсіяння світла нанорозмірних суперіонних провідників пояснені домінуючим впливом поверхневих фононних мод. 